\title{
The Emerging Knowledge Governance Approach Challenges and Characteristics
}

\author{
Foss, Nicolai J.
}

Document Version

Final published version

Publication date:

2006

\section{License \\ CC BY-NC-ND}

Citation for published version (APA):

Foss, N. J. (2006). The Emerging Knowledge Governance Approach: Challenges and Characteristics. DRUID Danish Research Unit for Industrial Dynamics. DRUID Working Paper No. 06-10

Link to publication in CBS Research Portal

\section{General rights}

Copyright and moral rights for the publications made accessible in the public portal are retained by the authors and/or other copyright owners and it is a condition of accessing publications that users recognise and abide by the legal requirements associated with these rights.

Take down policy

If you believe that this document breaches copyright please contact us (research.lib@cbs.dk) providing details, and we will remove access to the work immediately and investigate your claim. 


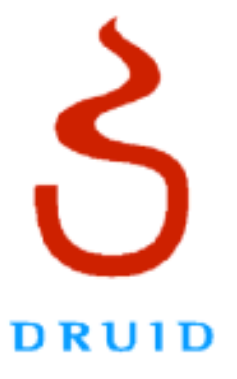

DRUID Working Paper No. 06-10

The Emerging Knowledge Governance Approach:

Challenges and Characteristics

By

Nicolai J. Foss 


\title{
3
}

D R U 1 D

\section{The Emerging Knowledge Governance Approach: Challenges and Characteristics}

\author{
Nicolai J. Foss \\ Center for Strategic Management and Globalization \\ Copenhagen Business School \\ Porcelainshaven 24B, $2^{\text {nd }} \mathrm{fl}$. \\ 2000 Frederiksberg, Denmark \\ E-mail: njf.smg@cbs.dk \\ and \\ Department of Strategy and Management \\ Norwegian School of Economics and Business Administration \\ Breiviksveien 40, N-5045 Bergen, Norway
}

11 July 2006

\begin{abstract}
:
The "knowledge governance approach" is characterized as a distinctive, emerging approach that cuts across the fields of knowledge management, organisation studies, strategy, and human resource management. Knowledge governance is taken up with how the deployment of governance mechanisms influences knowledge processes, such as sharing, retaining and creating knowledge. It insists on clear micro (behavioural) foundations, adopts an economizing perspective, and examines the links between knowledge-based units of analysis with diverse characteristics and governance mechanisms with diverse capabilities of handling these transactions. Research issues that the knowledge governance approach illuminates are sketched.
\end{abstract}

Key words: Governance, knowledge management, organizational economics JEL Codes: L1, L2, M1

ISBN 87-7873-201-8 


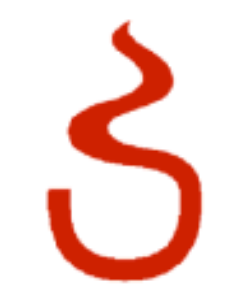

D R U 1 D

\section{Acknowledgments}

I am grateful to participants in 2005 EGOS conference for comments on the talk that formed the basis of this paper, to Andreas Scherer for urging me to put my thoughts in a written format, to Peter Abell, Teppo Felin, and JC Spender for very stimulating discussions on various occasions of fundamental issues that are treated in this paper, and to four anonymous reviewers for truly excellent feedback. Thanks to Yvonne Borkelmann for research assistance. 


\section{INTRODUCTION: AN EMERGING APPROACH}

The purpose of this article is to characterize an emerging approach - the "knowledge governance approach" (henceforth, the "KGA") — in terms of how it differs from other parts of the knowledge-based literature, the problems it seeks to solve, and the methods and ideas it applies. ${ }^{1}$ The approach may be briefly defined as a sustained attempt to uncover how knowledge transactions - which differ in their characteristics — and governance mechanisms — which differs with respect to how they handle transactional problems —, are matched, using economic efficiency as the explanatory principle. In terms of intellectual underpinning, the KGA largely takes its cues from organizational economics (particularly transaction cost economics), but also recognizes a need to go beyond this body of thought in terms of the treatment of motivation and cognition on the level of individuals (cf. Grandori, 1997; Osterloh and Frey, 2000), how transactions are dimensionalized (cf. Nickerson and Zenger, 2004), and the set of governance mechanisms that are considered (cf. Grandori, 2001). Cutting thematically across the fields of knowledge management ("KM"), human resource management, organization theory, and strategic management, the KGA starts from the hypothesis that knowledge processes (i.e., the creation, retention, and sharing of knowledge; Argote, 1999) can be influenced and directed through the deployment of governance mechanisms, in particular the formal aspects of organization that can be manipulated by management, such as organization structure, job design, reward systems, information systems, standard operating procedures, accounting systems, and other coordination mechanisms (cf. Grandori, 2001). The KGA asserts that such governance mechanisms should be seen as critical antecedents of knowledge processes.

Philosophically, the KGA asserts the need to build micro-foundations based in individual action and interaction for organizational knowledge-based phenomena (knowledge sharing, organizational knowledge creation) (i.e., “methodological individualism,” cf. Hayek, 1952; Coleman, 1990; Felin and Foss, 2005); it attempts to trace the specific mechanisms through which organization exerts its influence on knowledge processes ("mechanism-based explanation”, cf. Hedström and Swedberg, 1996; Machamer, Darden, and Craver, 2000); and it is unabashedly rational(istic) in its approach to explanation on the scientific domain and to organization design on the managerial domain (Williamson, 1996).

\footnotetext{
${ }^{1}$ The term "knowledge governance” seems to have been first used by Grandori (1997).
} 
The paper is structured as follows. I begin by locating the KGA in the overall "knowledge movement," that is, the broad interest in the management of knowledge that has characterized many fields in business administration during the last decade. However, this movement is beset by some fundamental weaknesses, and the KGA has arisen as a response to these weaknesses. The paper ends by giving a characterization of the KGA in terms of the problems it addresses and how it may solve these. Examples of existing research that may be seen as lying within the KGA are provided.

\section{WHY THE KNOWLEDGE GOVERNANCE APPROACH?}

\section{The Knowledge Movement}

"Knowledge" has been all the rage for more than a decade in a number of fields in management studies (e.g., Grandori and Kogut, 2002; Eisenhardt and Santos, 2003). A "knowledge movement" that cuts across traditionally separate disciplines in business administration has emerged. The strategy field has witnessed a proliferation of approaches that all place knowledge center stage (e.g., Grant, 1996; Spender, 1996; Kogut and Zander, 1996); the international business field is in the process of developing a view of the multinational corporation as a knowledge-based entity (Tallman, 2003); network ideas that stress connections between knowledge nodes, often based on sociological notions of network ties (Granovetter, 1973), are becoming increasingly influential (Kogut, 2000; Ghoshal and Tsai, 1998; Tsai, 2001, 2002); and, of course, KM has become not only a huge body of literature, but also a widespread organizational practice (Easterby-Smith and Lyles, 2003; Spender, 2005).

It is appropriate to characterize all this as a "movement" because of the shared conviction that the management of knowledge of whatever kind has become a critical issue for competitive dynamics, international strategy, the building of resources, the boundaries of firms, and many other issues. There is also agreement that it is meaningful to speak of different kinds of knowledge, each implying different management needs. And there seems to be an inbuilt pluralism to the knowledge movement, an agreement that no single established business administrative field or social science perspective is likely to carry us all the way towards a comprehensive understanding of the management of knowledge.

Those scholars who may be seen as working with the KGA are sympathetic fellow-travellers in the overall knowledge movement. However, the KGA stands out as a distinctive part of the knowledge movement because its points to a number of central problems that have not yet been satisfactorily addressed, and because there is a specific unity to the approach taken to solve 
such problems. Before the boundaries of this emerging approach can be identified, it is necessary to discuss the gaps in the extant literature that the KGA has arisen as a response to.

\section{Research Gaps}

As indicated the knowledge movement is broad and highly diverse in terms of research interests, underlying disciplines, research methods, results, philosophical underpinnings, etc. In fact, the knowledge management field alone is highly diverse. Nevertheless, there are a number of distinct shared research gaps in the knowledge movement that the KGA may be seen as reacting to. To get an idea of what these may be, consider the following two examples: 1) the governance of knowledge intensive firms (Starbuck, 1992) or "human capital organizations," and 2) the importance of knowledge for competitive advantage. There are serious gaps in our understanding of these and the KGA may help close the gaps.

Governance of human capital organizations. "Human capital organizations" are organizations where a significantly larger part of value-added can be ascribed to human than to physical assets. They range from R\&D-intensive manufacturing firms to professional services firms, and rely on scarce "expert talent." These changes with respect to an increasing human capital component of firms' productive inputs are often argued to take place in tandem with an increase of the "knowledge-content" in outputs, a stepping up of innovative activity, an increasing differentiation of demand, increasing globalization, and increasingly inexpensive networked computing - complementary changes that are taken to indicate the emergence of the “knowledge economy” (Halal and Taylor, 1998), or at least a new paradigm of “modern manufacturing” (Milgrom and Roberts, 1990).

Fundamental changes in economic organization are also implied by the increased prevalence of human capital organizations, as reflected in notions of the "changing employment contract," "new organizational forms," “internal disaggregation," etc. In particular, many scholars have argued that the boundaries of firms are being radically transformed, not just because firms increasingly disaggregate (i.e., outsource, spin-off, etc.), but also because the very notion of firm boundaries is becoming increasingly problematic as (inalienable) human capital increasingly dominates (alienable) physical capital as the most important category of productive capital (see Foss, 2002).

As this suggests, the advent and increased prevalence of human capital organizations have profound implications for the deployment of governance mechanisms such as the allocation (and exercise) of authority and the design of reward systems. In fact, according to a viewpoint 
that has almost acquired the status of conventional wisdom, human capital organizations may be differentiated from "traditional" firms in terms of governance mechanisms by relying less on direction through the exercise of authority, eschewing high-powered performance incentives, and embracing "culture” and "clan” modes of organizational control (at least for the core group of employees) (e.g. Child and McGrath, 2001). Organizational control is exercised through very different mechanisms in the two kinds of firms.

However, Teece (2003) develops a completely contrary view. Teece explains how the organization of his own firm (Law and Economics Consulting Group, LECG), a professional services firm, is very much different from the above portrayal of how human capital organizations are administered and controlled. In particular, while indeed the traditional blunt authority-mechanism (supervision, order-giving) is "extremely weak" in this firm, very highpowered performance incentives are used (instead). The two features are related, for by setting compensation for "experts” “... purely as a certain percentage $\alpha$ of the expert's own individual bill-out rate times hours worked (as accepted by the client)” (Teece 2003: 909), strong incentives are coupled with a small need for monitoring. Teece speculates that the specific organizational design of LECG (and there are other features in addition to those briefly mentioned here) “... may well portend the future for professional service organizations endeavouring to leverage top talent” (p. 914).

The point is, of course, not that Teece is right and those who argue differently are wrong, or vice versa. Both may be right - for different kinds of human capital organizations or for different environments. The problem is rather that we do not have a good theory that will allow us to discriminate between these alternative accounts in a clean manner. Such a theory would start from a knowledge-related unit of analysis and explain how the efficient deployment of governance mechanisms systematically varies when the unit of analysis varies, given assumptions about agents' knowledge and motivation and given assumptions about the principle (e.g., efficiency) that links the unit of analysis with alternative kinds of governance mechanisms (or combinations thereof).

Knowledge and competitive advantage. Strategic management may well be the field in business administration (at least among the more traditional/well-established fields) where knowledge-based approaches have been developed and applied with the greatest success (measured in terms of overall influence in a field) (e.g., Kogut and Zander, 1992; Grant, 1996; Spender, 1996; Kogut, 2000). Thus, the dominant resource-based view, while not logically 
committed to placing knowledge resources center stage nevertheless often does exactly this. The underlying argument seems to be that knowledge resources empirically are particularly often the cause of competitive advantages and are particularly difficult to imitate. In particular, much interest has centred on knowledge constructs such as capabilities that are placed on the firm-level, as primary examples of value-creating and difficult to imitate resources. A key idea here is that differential firm performance can be traced to differential capabilities; successful firms control capabilities that result in more appropriable value-added than less successful firms. However, the explanatory stance typically taken in the resource/capabilities view is not satisfactory. There are two reasons for this.

First, the literature reasons directly from something placed on the firm-level (i.e., capabilities are antecedents) to something else that is also placed on the firm-level (e.g., competitive advantage). Aggregates are directly linked to (in fact, claimed to cause) other aggregates. This is known as "methodological collectivism” (Hayek, 1952; Coleman, 1990). In short, this stance is problematic because it suppresses the level of individual action and interaction. A recent attack on collectivism in strategy research has been launched by Lippman and Rumelt (2003). They point out that arguing that "firms" (i.e., collective entities) earn a residual return called "profits" is highly misleading. In particular, it obscures the complex process of appropriating value where the appropriation is not undertaken by firms (and certainly not by "capabilities") but by the firm's stakeholders that come equipped with different bargaining powers. Thus, a “collectivist” approach obscures important micro-mechanisms. In the present context, what is obscured is the issue of how knowledge that ultimately resides on the level of the individuals is somehow integrated through organizational means into organization-level capability, and how this integration results in knowledge being utilized in such a manner that competitive advantage becomes the result.

Second, the collectivist capabilities perspective in strategy neglects organization — and does so at its peril. Although capabilities are often taken to be organizational processes that enable managers to carry out certain key tasks, organization itself seems almost conspicuous by its absence in most capabilities work. By "organization" is here understood the formal and informal allocation of decision (or property) rights and the mechanisms that enforce such rights (Jones, 1983). This rights allocation and the accompanying enforcement mechanisms constitute the distribution of authority, the attributes of governance mechanisms, organizational structure, and other aspects of formal organization, but clearly also relates to, for example, social ties and networks inside firms. An allocation of property rights is also an allocation of incentives 
(Barzel, 1997), including incentives to search for knowledge, share knowledge, accumulate human capital, leverage knowledge capital, etc. (Foss and Mahnke, 2003); moreover, property rights influence bargaining powers (Hart, 1995). For example, social ties and networks — much emphasized in KM research — are important for understanding the links between knowledge and superior returns, not just because of their potentially beneficial effects on returns, but also because such ties and networks grant legitimacy to the claims that employees may make on rents (Coff and Blyler, 2003). In turn, these appropriation issues matter to knowledge processes, because employee incentives to search for, share, create, and integrate knowledge are influenced by how much they can appropriate (Coff, 1999).

\section{Causes of Research Gaps}

There are probably many reasons why the above research gaps exist. The following discuss some of the major causes, concentrating on the missing micro-foundations in the knowledge movement and the neglect of governance mechanisms as antecedents of knowledge processes.

Missing micro-foundations. Consider Figure 1 which builds on the work of sociologist James Coleman (1990).

Figure 1: A General Model of Social Science Explanation

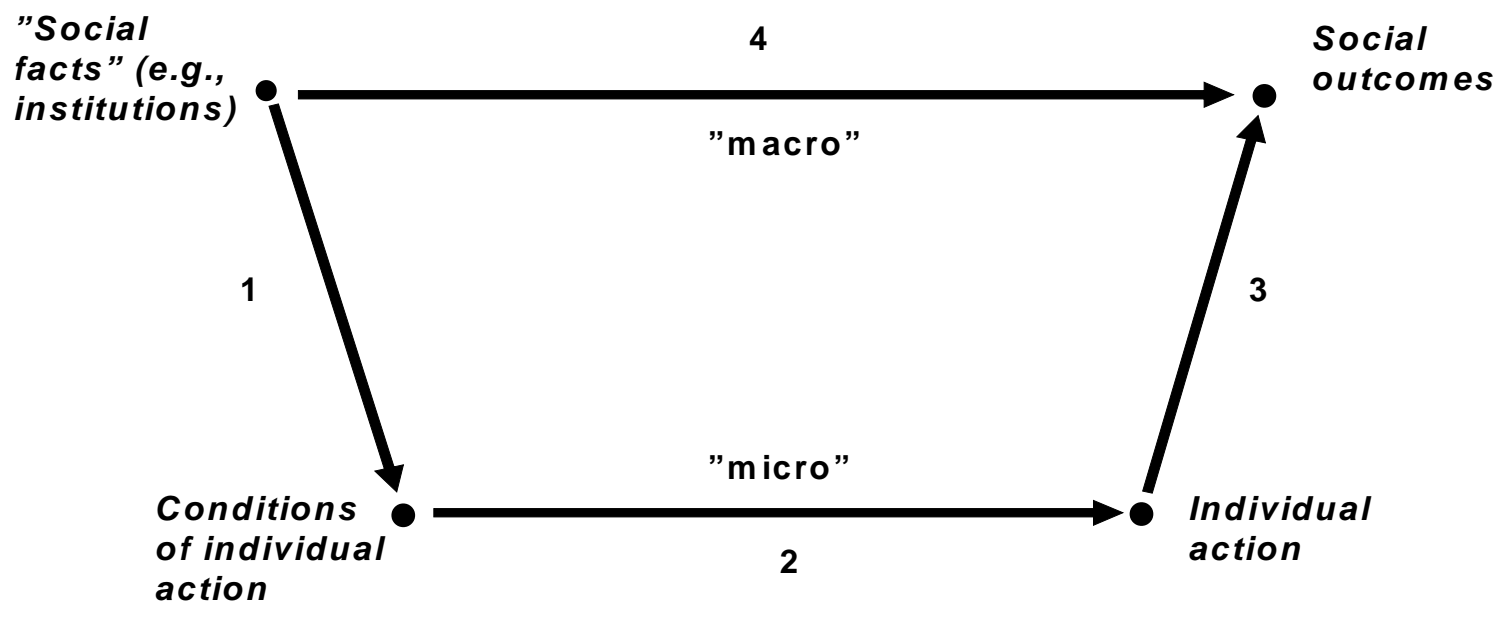

The figure makes a distinction between the macro-level and the micro-level. For example, it may be that the macro-level is organizational whilst the micro-level is that of individuals. As shown, there are links between macro-macro (arrow 4) and macro-micro (arrow 1), micro- 
micro (arrow 2), and micro-macro (arrow 3). The figure also makes a distinction between what is to be explained (i.e., the explanandum) and its explanation (the explanans). Usually, the aim is to explain either a macro-level phenomenon (located in the upper right hand corner of figure 1), such as a firm-level outcome, or a correlation between macro-phenomena (i.e., arrow 4). In order to explain the analyst makes use of theoretical mechanisms implied by the arrows (Hedström and Swedberg, 1996; Machamer, Darden, and Craver, 2000). Note that the arrows in Figure 1 are, from a theoretical perspective, empty boxes. They may be filled with different kinds of theoretical mechanisms, quite dependent on the choices of the analyst.

The Coleman diagram can be used to diagnose in a more precise manner some of the problematic features of extant work in the knowledge movement; see Figure 2.

Figure 2: Capabilities as Antecedent to

Competitive Advantage

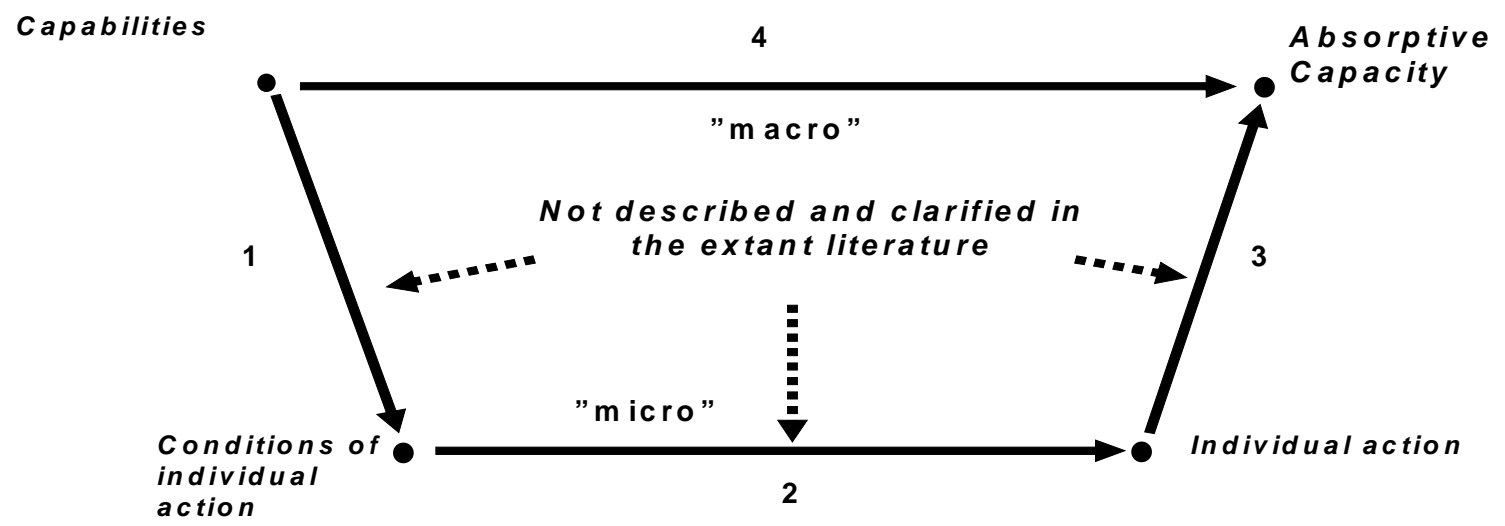

Consider again the strategic management manifestation of the knowledge movement, that is, the capabilities (or knowledge-based) view (e.g., Kogut and Zander, 1992, 1996). In terms of the diagram depicted in Figure 2, capabilities theorists usually posit a direct relation between capabilities and competitive advantage, that is, they make use of arrow 4. However, arrow 4 explanation can only be used under special circumstances and only as a shorthand way of representing more complex underlying behaviours. The reason is fundamentally ontological: There are no conceivable mechanisms that directly take us from the organization-level construct of capability to organization-level outcomes such as competitive advantage. A research gap in the capabilities view therefore concerns accounting for the impact on performance of capabilities in terms of other, more "micro" mechanisms (arrows 1, 2 and 3). There is, of 
course, a substantial KM dimension to this. For presumably firm-level capability is, among other things, a reflection of representations, beliefs, information, etc. that, ultimately, is held by individual employees, and utilizing this knowledge in an optimal manner is a key KM task. Thus, talking of the need to manage capabilities for the purposes of achieving competitive advantage is simply shorthand for a KM task that inherently involves the micro-level of organizations.

Organizational antecedents. The Coleman diagram is also useful for understanding the role that organizational antecedents play in the knowledge movement. Such antecedents may be thought of as being placed at the North-Eastern node in figure 2 (i.e., substitute "capabilities" with "governance mechanisms"). The deployment of information systems, incentive schemes, allocations of decision rights and authority, and so on directly impact on the conditions of individual action. Governance mechanisms is, of course, deployed in the belief that influencing the conditions of actions (the south-eastern node) in a certain manner will lead employees to take those decisions (the south-western node) that, when aggregated (arrow 3), lead to favourable organizational outcomes (the North-Western node in figure 1). Thus, the attempt to better exploit certain knowledge assets through knowledge sharing (an organizational outcome) may be implemented by setting up reward systems for knowledge sharing (and knowledge searching), installing monitoring mechanisms that make sure that knowledge that is shared (and for which rewards are paid) is actually relevant knowledge, and so on.

In general, the knowledge movement has a problem with organizational antecedents. To be sure, organization issues often do get mention in various discussions of knowledge processes within and between firms ${ }^{2}$ (e.g. Hamel, 1991; Hedlund, 1994; Lyles and Schwenk, 1992). Special issues of journals have been devoted to the theme of the link between organization and knowledge processes (e.g., Journal of International Business Studies, vol. 35, no.5, 2004; Journal of Management Studies, vol. 38, no.7, 2001). A recent (excellent) textbook on KM (Hislop, 2005) discusses communities of practice, boundary-spanning processes, power and conflict, ICT, culture and HRM issues, virtual organizations, MNC and knowledge-intensive

\footnotetext{
2 The organization/knowledge-and-information link is certainly not a recent one either, as many writers have argued that organization is responsive to knowledge and information and that in turn organization may shape knowledge and information. Thus, on a fundamental level the information-processing emphasis in organization theory of the 1960s and 1970s illustrates the first causality, and earlier, Hayek's (1945) famous argument concerning the need for decentralization when relevant knowledge is "knowledge of time and circumstance" makes a similar point on an even more abstract level. Less abstractly, the innovation management literature has long stressed that such organizational issues as role definition, team composition, the distribution of authority, and communication efforts should be very much responsive to the nature of the development effort (e.g., Clark and Fujimoto, 1991).
} 
firms, all in separate chapters. In sum, it would be factually incorrect to argue that the knowledge/organization link is a neglected one. However, some critical observations are still pertinent here.

First, it is characteristic that many contributions to the organization-knowledge link have a collective(ist) orientation in the sense that the analytical reduction indicated in figures 1 and 2 is not performed. Instead, the explanation takes place solely on the collective level; for example, theorists discuss the role of "communities of practice" (Brown and Duguid, 1998) — that is, collective entities - for organization-level knowledge. As a telling example, in none of the contributions to the Journal of Management Studies special issue on KM do we find an explicit attempt to link organization and knowledge by means of mechanisms corresponding to arrows 1,2 and 3 in figure 1.

Second, it is characteristic that "organization" predominantly means "informal organization", that is, networks, culture, communities of practice, and the like, rather than formal governance mechanisms. The allocation of authority and decision rights, the provision of incentives, and the creation of organizational structure may be invoked - but they are seldom if ever integrated into the analysis. A good example of this tendency is recent work on knowledge sharing and innovation that takes Granovetter (1973) as the main theoretical foundation. For example, Tsai (2001) argues that if organizational units occupy a more central network position, they perform better in terms of innovation. Social networks facilitate new knowledge creation within organizations. Hansen (2002) develops a concept of "knowledge networks" to explain why some business units are able to take advantage of knowledge that resides in other parts of the organization, while other units may not be. And so on. In almost all of this kind of work, there is a neglect of formal organization. ${ }^{3}$ For example, the issue of incentive compatibility in situations where employers wish employee to expend effort on searching for and sharing knowledge, and how various kinds of rewards may (or may not) prompt the desired behaviours have been surprisingly neglected

Organizational costs. Foss and Mahnke (2003) note that the KM literature in particular, and arguably also the knowledge movement at large, are strangely innocent of notions of cost (save, of course, for mention of costs of setting up IT systems). In particular, organizational costs, they note, are almost universally ignored. Because of these neglects the question of whether

\footnotetext{
${ }^{3}$ An exception is Tsai (2002) which indicates that formal hierarchical structure, in the form of centralization, has a significant negative effect on knowledge sharing. In contrast, informal lateral relations, in the form of social interaction, have a significant positive effect on knowledge sharing.
} 
knowledge sharing is always beneficial is seldom raised. Thus, maximum knowledge sharing is implicitly assumed to be desirable, although, of course, optimum knowledge sharing is never equal to maximum knowledge sharing.

Organizational alternatives. Although the issue of organizational alternatives for knowledge processes (e.g., knowledge sharing) gets mention in the knowledge movement, alternatives are seldom confronted in terms of an economizing logic. The reason lies in the absence in the literature of an explicit cost calculus related to knowledge processes and the organization thereof. In the absence of any such (transaction) costs, decision-makers would immediately pick those knowledge-related activities that maximize value creation (Coase, 1960; Foss and Foss, 2005). Moreover, how these activities were organized would not matter for value creation (Coase, 1937).

However, in the presence of costs of, say, sharing knowledge the issue of organizational alternatives becomes pressing. For example, a relevant alternative to knowledge sharing may sometimes be more delegation of decision rights: If the problem is to make better use of existing knowledge, it can be better to allow the employees who hold this knowledge to make better use of it than to spread it to the rest of the organization. What is best depends on the net benefits associated with each alternative. However, such comparative assessments are virtually never performed.

The neglect of organizational costs is accompanied by a neglect of not only organizational alternatives, but also of formal organization. If only informal organization is considered, there is a tendency to become less normative. A concern with formal organization (as in the organization design literature; e.g., Mintzberg, 1979) is usually accompanied by an attempt to devise efficient organization; such a normative ambition appears to be much less prevalent when the concern is with informal organization. ${ }^{4}$ The attempt to devise efficient organization involves a consideration of organizational alternatives that are evaluated relative to some yardstick, such as net benefits. Such a normative enterprise is a key component of the KGA.

\footnotetext{
4 This is hardly surprising, as many of the components of informal organization, such as culture, are semipermanent traits of an organization that may be harder to change than organizational design variables such as the components of organizational structure, reward systems, etc. In the language of optimal control theory, informal organization variables are more like "state variables" whereas formal organization variables are more like "control variables.”
} 


\section{WHAT IS THE KNOWLEDGE GOVERNANCE APPROACH TRYING TO ACCOMPLISH? PROBLEMS AND HEURISTICS}

\section{Knowledge Governance Problems}

The KGA identifies, grapples with, and solves problems that lie in the intersection of organization and knowledge processes, problems that for various reasons are hard to approach and solve within other knowledge-based approaches or where these approaches give a different solution than the KGA. In the following, examples of such problems are provided and discussed.

Motivation and knowledge processes. The KGA stresses micro-foundations, implying that a starting point is taken in behavioural assumptions. In contrast, explicit behavioural assumptions are seldom made in knowledge-based contributions (but see Kogut and Zander, 1996). The choice of behavioural foundations is partly determined by the kind of questions to which answers are sought.

For example, Osterloh and Frey (2000) examine how knowledge transfer is influenced by organizational design. This research question is embedded in a broader discussion of how firms increasingly introduce market elements to exploit the advantages of price mechanisms, by making exchanges between departments or actors more explicit and enabling them to reward according to the contribution to a firm's profit. In order to theorize the mechanisms lying between organizational variables and organizational-level knowledge sharing, the authors begin by identifying a number of exchange hazards that beset internal knowledge transactions. They argue that the transfer of tacit knowledge cannot be accomplished by contracting, and that employees cannot be sanctioned for holding back tacit knowledge. Therefore, the management of individual motivation becomes central. Firms have access to mechanisms (that markets don't) to manage intrinsic motivation, such as participation which signifies agreement on common goals and raises employees' self-determination, thereby strengthening intrinsic motivation and personal relationships, which allows for establishing psychological contracts based on emotional loyalties, which in turn raise the intrinsic motivation to cooperate. In contrast, to heavy-handed use of market-like incentives may destroy intrinsic motivation (i.e., the "crowding effect"). To develop the argument the authors rely on psychological theories of individual motivation.

Like Osterloh and Frey, Foss (2003) argues that infusing hierarchies with market control in order to increase knowledge sharing and creation is inherently difficult. The argument in this 
paper is that there is a fundamental incentive problem of establishing credible managerial commitments to not intervene in delegated decision-making (and heavy delegation is an integral part of "internal hybrids). The argument is illustrated with the case of the organizational transformations that took place in the 1990s in the world-leading hearing aids producer, Oticon. Frequent managerial meddling with decision rights that, in accordance with the official Oticon culture, had been delegated to employees led to a severe loss of motivation, and arguably caused the change to a more structured organization from the earlier extremely decentralized form. Thus, in order to understand the influence of organizational form on knowledge processes, this paper, like Osterloh and Frey (2000) focuses on the level of individual employees and their motivation.

These two papers provide insights into the motivational aspects of conscious management efforts to influence knowledge processes by means of the deployment of governance mechanisms. However, one paper is purely theoretical (Osterloh and Frey) while the other single-case-based (Foss). More systematic evidence needs to be assembled on these motivational dimensions of knowledge governance. In addition theoretical inquiry is needed into issues such as which kinds of incentives (and which incentive intensities) work best for which kind of knowledge processes. Conceivably, one kind of incentive may work for knowledge sharing but not for knowledge production. Or, only the strength of the incentives provided should differ. Or, the incentives may be exactly the same. Or, they may only work if combined with other kinds of incentives. In sum,

KGA Research Question 1: What is the impact of different kinds of (systems and strength of) incentives on knowledge sharing, integration and creation, taking into account the complex dynamics of motivation (e.g., the crowding effect)?

Deploying governance mechanisms to influence knowledge processes. The issue of what governance mechanisms are chosen to steer knowledge sharing, integration and creation relates to organizational choice in a broad sense, that is, it includes choices between the two levels of analysis of governance structures ${ }^{5}$ and organizational forms, that is, the specific combination of elements of governance mechanisms inside organizational forms. Consider the following examples of analyses that relate to these two levels of analysis.

Nickerson and Zenger (2004) seek to explain how alternative organizational forms influence the efficient production of valuable knowledge. The unit of analysis for knowledge generation is a

\footnotetext{
${ }^{5}$ In the sense of Williamson (1996), that is, the choice between hierarchies, hybrids, and markets.
} 
specific problem, whose value is determined by the values in the array of possible solutions and the cost of discovering a particularly valuable problem. The solution to complex problems is assumed to represent unique combinations or syntheses of existing knowledge. Problems differ according to their decomposability. Decomposable problems involve limited interaction, whereas non-decomposable problems involve extensive interaction. This has important implications for the type of searching for a solution. Directional search refers to classic trial and error search. It is efficient only for decomposable activities. Heuristic search refers to a group or team cognitively evaluating probable consequences of design choices.

Non-decomposable problems require individuals to share their specialized knowledge. The ability or motivation to share knowledge is impeded by two conditions: humans are cognitively constrained in the speed with which they learn and are prone to self-interest. The wide distribution of knowledge in conjunction with self-interest leads to two knowledge-related exchange hazards: knowledge appropriation and strategic knowledge accumulation. Consequently, efficiency considerations dictate the selection of an optimal governance mechanism and the provision of incentives. Three distinct governance structures and their suitability for problems with differing characteristics are examined: markets, authority-based hierarchies and consensus-based hierarchies. Briefly, markets are ideally suited when problems are decomposable and directional search is desired; consensus-based hierarchy creates high organizational costs and should only be adopted when the benefits for consensus are high, which is for problems that are highly complex and non-decomposable; finally, authority-based hierarchy is superior to markets in supporting heuristic search, but inferior in supporting directional search. The authors propose that authority based-hierarchies are best suitable for a range of problems that are moderately complex.

Osterloh and Frey (2000) and Foss (2003) examine the impact of organization form on knowledge processes, making a sharp distinction between firms and markets. The implicit argument is that "discrete structural alternatives" such as firms and markets can be sharply distinguished because of strong complementarities between the constituent organizational elements (Milgrom and Roberts, 1990; Williamson, 1996). However, an open issue concerns how strong such complementarities are. A prevalent claim is that they tend to become less binding in the knowledge economy, as traditional organizational forms have difficulties efficiently organizing knowledge-transactions, giving rise to networks that mix firm and markets and cut across the boundaries of firms (Liebeskind et al., 1996). 
Grandori (1997, 2001) analyzes the various kinds of governance mechanisms that govern the transfer, sharing and integration of knowledge between and within firms. Firms have enriched their knowledge management systems with explicit mechanisms to provide incentives for knowledge integration. Grandori (2001) argues that not only hierarchical and (what she calls) “communitarian” mechanisms are usually applied, but also price-based (market-like) contracts and decentralized, but not identity-based mechanisms. She concludes that the portfolio of mechanisms that are effectively employable between firms to link nodes of specialized knowledge can hardly be distinguished from those mechanisms employable within firms. An implication of her discussion is a denial of the strong emphasis on organizational elements that can be found in large parts of organizational theory.

Grandori certainly has a point in suggesting that organizational theorists may too strongly have emphasized the theme of complementarity between "governance mechanisms," and that too much emphasis (therefore) has been on "discrete structural forms" of organization. She may also be right that the increasing importance of the sourcing, coordination and deployment of knowledge inputs in production makes complementarities between elements of governance mechanisms less strong. However, Grandori may also be wrong. Clearly, what is needed here is (again) more systematic empirical knowledge. However, more theoretical inquiry is similarly needed into how different combinations governance mechanisms may impact knowledge processes. Very little of this kind of design-oriented research exists (e.g., Siggelkow and Rivkin, 2005). ${ }^{6}$

KGA Research Question 2: What combinations of governance mechanisms are best suited for promoting knowledge sharing, integration, and creation within and between firms? ${ }^{7}$

Identifying knowledge-based hazards? Osterloh and Frey (2000), Grandori (2001) and Foss (2003) all more or less explicitly argue that knowledge processes have a number of salient features that set them apart from many "ordinary" business processes (e.g., coordinating

\footnotetext{
${ }^{6}$ Some initial empirical investigations are Laursen and Foss (2003) who empirically examine the impact of new HRM systems on innovation, Minbaeva et al. (2003) who examine how HRM in the subsidiaries of multinational firms impact knowledge transfer within such firms, and Foss (2003) who use a case study to argue that the combination of a strong authority mechanism (implying frequent managerial intervention) with a high degree of delegation and project-based organization is an inefficient one for the purpose of knowledge creation.

${ }^{7}$ A derived research issue - too complicated and encompassing to treat in detail here - concerns the interaction of formal and informal elements of organization with respect to knowledge processes. For example, may formal reward systems for knowledge sharing be destructive of psychological contracts that encourage knowledge sharing? Some of this is touched upon in Osterloh and Frey (2000).
} 
logistics, running an assembly line, making a contract with a supplier, etc.), and that the increasing importance of knowledge processes has an impact on which kinds of governance mechanisms can be deployed how and in which combinations. However, a deep and systematic analysis of what sets knowledge processes apart from ordinary business processes in terms of giving rise to organizational problems or hazards is largely missing from the literature.

This is highly problematic, as arguments concerning the deployment of administrative machinery to influence knowledge processes must ultimately be based on analysis of which kind of knowledge-related problems such deployment is supposed to solve. Moreover, existing claims may be contested. For example, Osterloh and Frey's arguments that the transfer of tacit knowledge cannot (at all?) be accomplished by contracting, and that employees cannot (at all?) be sanctioned for holding back tacit knowledge are questionable; for example, agreements can be made that a senior employee accept a new employee as an apprentice and the outcome of the arrangement can to a certain extent be monitored. In sum, what is needed is a more thorough understanding of the organizational hazards that knowledge processes may give to and how these may be remedied by means of governance mechanisms (cf. also Buckley and Carter, 1996; Heimann and Nickerson, 2002).

KGA Research Question 3: What are the peculiar organizational and exchange hazards of knowledge processes, and how does the deployment of governance mechanisms remedy such hazards?

While the above research questions are highly abstract (and, of course, do not exhaust the space of possible overall KGA research questions), they are 1) fundamental, 2) unique to the KGA, and 3) necessary to address in order to undertake more applied research. For example, hypothesis development relating to how multinational corporations leverage human resource management systems to promote knowledge sharing (cf. Minbaeva et al., 2003), research into how governance mechanisms are deployed to knowledge-based strategic alliances (Mowery et al., 1996; Oxley, 1997; Heimeriks and Duyster, 2006), or the understanding of the governance of human capital organizations (Child and McGrath, 2001; Teece, 2003), the organizational antecedents to absorptive capacity (Janssen et al., 2005), the knowledge-based underpinnings of competitive advantage, the link between control of knowledge assets and the appropriation of surplus from relations (Coff, 1999; Coff and Blyler, 2003), and the provision of incentives to knowledge workers (Osterloh and Frey, 2000), are furthered to the extent that they are framed 
in ways that are akin to the above research questions and build on the answers that can be given to these questions.

\section{Explanation in the Knowledge Governance Approach}

In terms of figure 1, the KGA identifies as its overall explanandum the relation between governance mechanisms and knowledge outcomes, recognizing that correlational analysis of the relation between these macro-entities and outcomes (i.e., arrow 4 in figure 1) is at best a starting point and that ultimately the relations need to be accounted for in terms of mechanisms that relate to arrow 1,2 and 3.

Microfoundations. KGA explanation starts with the individual agent (even though it may be permissible to introduce more collective concepts, such as organization structure, in the analysis as shorthand). This implies modelling (i.e., making specific assumptions about) individual agents’ preferences, knowledge, incentives, etc. This emphasis on individualistic foundations as an attempt to meet the lacunae left in the knowledge movement by the overriding emphasis on collective constructs. As Argote and Ingram (2000: 156) noted, to the extent that there has been progress in studying knowledge as the basis of competitive advantage, “... it has been at the level of identifying consistencies in organizations' knowledge development paths and almost never at the level of human interactions that are the primary source of knowledge and knowledge transfer." The knowledge governance approach attempts to address this "primary source” by taking an explicitly individualistic approach. For example, the fundamental idea of Osterloh and Frey (2000) is understandable only if the analysis explicitly begins from individual motivation. More generally, the KGA asserts that many insights (including those that will emerge from addressing the research questions outlined above) cannot be reached in lieu of a starting point in individuals.

However, the question is, which micro-foundations? The general guideline is that this depends on the questions one tries to solve. Thus, economists have found that they have had to increasingly change the way they model individual cognition and motivation towards greater realism as they have moved from treating only market and macro-phenomena to also address contracts, organizations, networks, trust, and so. Moreover, a general rule is that the lower the level of analysis, the more fine-grained the description of the individual agent (Machlup, 1967).

Because the KGA is intimately concerned with how the deployment of specific governance mechanisms impacts knowledge processes (i.e., a low level of analysis), rather specific assumptions need to be made about individual agents, and these assumptions must "allow for" 
the phenomena to which an explanation is sought. Thus, assumptions that agents are always highly informed and docile will not assist the KGA.

While the KGA is sympathetic to the behavioural assumptions of transaction cost economics that is, bounded rationality and opportunism (Williamson, 1996) — , as these allow for the kind of organizational and exchange hazards that the KGA is concerned with, these behavioural assumptions may still be too coarse. Thus, "bounded rationality” means many things and “opportunism” may manifest itself in multiple ways. Moreover, bounded rationality and opportunism are not given, but can be influenced by governance mechanisms. Relatedly, a more sophisticated view of motivation (e.g., as in Osterloh and Frey, 2000) than is conventional in the economics of organization must be included in the KGA. Rather than merely representing the personal aesthetics of the present author, this reflects that a more nuanced view of motivation, one that is informed by advances in social psychology and organizational behaviour, seems necessary to capture the full complexity of the mechanisms that link governance mechanisms and knowledge processes (Grandori, 1997, 2001; Osterloh and Frey, 2000; Lindenberg, 2003; Cabrera, Collins, and Salgado, 2006.).

Unit(s) of analysis. It has been argued that the absence of a clear unit of analysis is a source of confusion in the knowledge movement at large (Williamson 1999). Is it routines (Nelson and Winter, 1982), or dynamic capabilities (Teece, Pisano and Shuen, 1997), or practices (Spender, 2005), or knowledge assets (Winter, 1987)? However, disciplines, fields, or approaches are not necessarily characterized by unique units of analysis. Thus, the existing diversity in the knowledge movement may simply reflect that different research problems are involved. Moreover, the emphasis on micro-foundations in the KGA does not dictate a specific unit of analysis, and is consistent with taking, for example, the "problem” (Nickerson and Zenger, 2004) or the "transaction" (Williamson, 1996) or a "knowledge unit" (Simonin, 1999; Contractor and Ra, 2002) as the unit of analysis. ${ }^{8}$ In general, what is the preferred unit of analysis should depend on the relevant research problems. The unit may differ depending on whether the focus is knowledge sharing or knowledge creation.

That being said, some units of analysis seem to be more generally applicable than others. Thus, Nickerson and Zenger (2004) construct a theory about the organization of knowledge creation, based on taking the problem as the unit of analysis. However, this seems primarily designed for

\footnotetext{
${ }^{8}$ Although notions of "firm-level" knowledge, such as "capabilities," do not seem to have a clear foundation in individual action, and will be avoided in the KGA.
} 
understanding the governance of knowledge creation (i.e., solving problems by combining knowledge); it seems less well-suited for understanding knowledge sharing or integration. ${ }^{9}$ The most generally applicable unit of analysis for the kind of problems that the KGA seeks to solve is the knowledge transaction, that is, the transfer of an identifiable "piece" of knowledge from one actor to another one. Knowledge transactions are involved in knowledge sharing, integration, and creation. Note that taking the knowledge transaction as unit of analysis has the added benefit of linking up with organizational economics and an established framework for linking transactions to alternative kinds of organizing.

Dimensionalizing knowledge transactions. However, the way of dimensionalizing transactions that has become dominant in organizational economics, namely the transaction cost economics triad of frequency/uncertainty/asset specificity, is at best incomplete for the purposes of treating knowledge transactions (cf. also Grandori, 2001; Heimann and Nickerson, 2002; Nickerson and Zenger, 2004). It is not clear how dimensionalizing a knowledge transaction in these terms assist the understanding of, for example, knowledge sharing where transactional problems may be caused more by the degree of codification of the relevant knowledge than its "uncertainty" (whatever that might mean in the specific context). The knowledge-based literature is unfortunately not entirely forthcoming with respect to dimensionalizing knowledge. ${ }^{10}$

An important exception is the Winter (1987) taxonomy, which has been the basis for much subsequent empirical work (e.g., Kogut and Zander, 1993; Simonin, 1999). Winter introduces the dimensions of tacitness vs. explicitness, system-quality vs. stand-alone, teachability vs. nonteachability, and complexity vs. non-complexity. Although these dimensions have usually been applied to more aggregate knowledge constructs (such as routines and capabilities) in the empirical literature, they can also be used to characterize knowledge transactions. Accordingly knowledge transactions can be dimensionalized in terms of the characteristics of the underlying knowledge. Clearly, there is no need to stop the process of dimensionalizing with the Winter taxonomy; other dimensions may be relevant. For example, scholars working from a transaction cost economics perspective have suggested adding “appropriability” as a relevant

\footnotetext{
${ }^{9}$ For example, in the case of knowledge sharing, the solution may be obvious (e.g., everybody should know X); however, the problem is inducing Jack to share X with Jill and other employees.

10 The many studies of inter-firm imitation and intra-firm knowledge transfer (e.g., Maritan and Brush 2003) tend to develop dimensions of, say, capabilities in an inductive manner and the explicit or implicit dimensionalizations differ from study to study.
} 
dimension (e.g., Oxley, 1997), ${ }^{11}$ and Contractor and Ra (2002) suggest adding how "novel” the knowledge is (knowledge with a higher degree of novelty is more costly to contract, absorb, assimilate, integrate, etc.). In the context of the KGA, the import of a dimensionalization of the unit of analysis is that the costs of sharing, integrating, and creating knowledge vary systematically with the relevant dimensions, and that the deployment of governance mechanisms to curb such costs should take this into account.

Organizational hazards. Knowledge transactions give rise to organizational hazards and costs depending on how they score in terms of the above dimensions. Thus, in the context of sharing knowledge, knowledge transactions that are characterized by [explicitness, stand-alone, high teachability, non-complexity] are likely to be significantly less costly to administer than knowledge transactions with the opposite characteristics. Transactions (in the context of knowledge sharing) that involve knowledge that is new, tacit, has significant system-quality, is hard to teach, etc. are associated with cost of transmitting the knowledge from sender to receiver, (measurement) costs of ascertaining the extent to which knowledge has been shared, (monitoring) costs of inspecting input performance, and other well known organizational costs.

Knowledge governance. As a positive approach the KGA shares a fundamental aim with the economics of organization: To examine how knowledge transactions — which differ in their characteristics - and governance mechanisms - which differs with respect to how it handles transactional problems - , are matched, using economic efficiency as the explanatory principle and given behavioural assumptions (cf. Williamson, 1996; Buckley and Carter, 1996; Grandori, 2001; Heimann and Nickerson, 2002; Nickerson and Zenger, 2004). As a practical and normative enterprise, knowledge governance means deploying governance mechanismses that mitigate costs of sharing, integrating and creating knowledge owing to the above characteristics of knowledge (Heiman and Nickerson 2002: 98). Knowledge governance therefore means deploying governance mechanisms so as to maximize the net benefits from processes of transferring, sharing and creating knowledge. This is similar to the transaction cost minimizing logic of transaction cost economics.

Consider some examples of such "efficient alignment.” Knowledge sharing usually involves at least two activities, minding one's ordinary job and sharing knowledge with somebody else. When the relevant knowledge is tacit, it is usually costly to write it into a formal agreement

\footnotetext{
${ }^{11}$ Appropriability is to some extent derivative of e.g., the tacitness vs. explicitness dimension, but not fully, as it also includes the legal framework surrounding the transaction.
} 
(Osterloh and Frey, 2000). Providing high-powered incentives to the presumed knowledge sharer leads to a "multi-tasking problem" (Holmström and Milgrom, 1991); the incentive is to concentrate effort on the measurable task and not on knowledge sharing which is costly to measure. Given tacitness, job-design and rewards are clearly related with respect to their impact on knowledge sharing. A related problem may arise in the case where firms design production and development teams as partly overlapping in order to improve lead-time (Clark and Fujimoto, 1991). In this situation, it can be dangerous to use performance-based rewards because of the externalities between the activities of the two teams. Given the system-quality of knowledge in this case, task allocation and the definition of organizational units interact with reward systems in influencing the generation of knowledge. A third example concerns the use of delegation in the context of the sharing of knowledge. Given that tacitness increases the costs of making explicit agreements, delegation of the right to initiate, carry out, etc. knowledge sharing with colleagues seems to be an efficient alternative to instructing employees to share specific knowledge. In contrast, when knowledge is explicit, such delegation appears to be less necessary.

The crowning achievement of the KGA will be a discriminating alignment framework that can organize examples such as the above, bring out the unifying logic, and allow for predictions. Some inspired beginnings in this respect are Grandori (2001), Heimann and Nickerson (2002) and Contractor and Ra (2002). At the present stage development, what is arguably most needed, however, is empirical work that can assist in identifying knowledge-based hazards, ascertain how organizations deal with such hazards by deploying governance mechanisms, find out how these mechanisms are characteristically combined, and examine the performance implications of knowledge. Empirical work that grapples with this kind of issues has emerged within the last five years or so (e.g., Foss, 2003; Heimann and Nickerson, 2004; Mayer and Argyres, 2004; Hoetker and Mellewigt, 2006; Macher, 2006). The body of work is not large, but it is growing and may be taken as evidence of the fruitfulness of the KGA.

\section{CONCLUSIONS: DEFINING THE KNOWLEDGE GOVERNANCE APPROACH}

Pondering the issue of what "knowledge approaches can contribute to organizational theory," Anna Grandori (in Grandori and Kogut, 2002: 225) observed that what can be contributed is “... a new 'contingency' factor for understanding organizational arrangements ... Knowledge complexity, differentiation, and specialization, complementarity and interdependence are emerging as important contingencies affecting effective organization and governance 
solutions.” Grandori is indeed correct that an increasing number of papers in organizational theory, organizational economics, international business, and strategic management incorporate new knowledge-based “contingency factors.” However, the contention of this paper is that one can go further and posit the existence of an emerging, distinctive approach — the "knowledge governance approach" — that is taken up with theoretically grounding and empirically exploring the interplay between knowledge-based contingency factors and organization.

Accordingly, the purpose of the paper has been to provide an identification of the KGA in terms of how it has arisen as a reaction to shortcomings in the knowledge movement at large, the problems it seeks to solve, and its approach to solving these problems. These three themes all center on the issue of micro-foundations: The KGA is unique in accounting for the micro-level mechanisms that link governance mechanisms and knowledge processes. It is fundamentally because of this micro-emphasis that the KGA can uphold the explanation (beyond correlation) of how governance mechanisms can influence knowledge processes as a key research question. Similarly, it is this emphasis that lends credence to the design ambitions of the KGA: Theories that explain and detail the mechanisms that mediate between instruments and outcomes are inherently more useful than theories that simply postulate a correlation (Coleman, 1990).

The emphasis on knowledge in a number of fields in business administration during the last two decades has been a major step forward. However, much of the relevant literature has been practice-driven and oriented towards prescriptions, and has had little or unclear disciplinary foundations. A hindrance for true application has been a certain explanatory naivety in much of this literature (e.g., the emphasis on ill-understood “capabilities”). The KGA can be seen as an attempt to simultaneously meet the insistence on practical applicability of, for example, the KM field and the insistence of relative rigour that characterizes fields such as organizational design theory or organizational economics. In that respect, it marks a return to the ideals that animated the organizational design literature of the 1960s and 1980s, which certainly also touched on issues that are related to the KGA (e.g., the concern with how organizational structure impacts information processes, the notion of “adhocracies” in Mintzberg [1979] which acknowledges organizations where human capital inputs are particularly important, etc.). In order to successfully meet both ambitions, much more work is needed within the KGA. This article has sketched the kind of work that should be done to further the KGA. 


\section{REFERENCES}

Alchian, Armen A. and Harold Demsetz (1972) 'Production, Information Costs, and Economic Organization,’ American Economic Review 62: 772-795.

Argote, Linda, Sara L. Beckman, and Dennis Epple (1990) 'The Persistence and Transfer of Learning in Industrial Settings,’ Management Science 36: 140-154.

Argote, Linda (1999) Organizational Learning: Creating, Retaining and Transferring Knowledge. Boston: Kluwer.

Argote, Linda and Paul Ingram (2000) 'Knowledge Transfer: A Basis for Competitive Advantage in Firms,' Organizational Behavior and Human Decision Processes, 82(1): 150-169.

Barnard, Chester I. (1938) The Functions of the Executive. Cambridge, MA: Harvard University Press.

Barzel, Yoram (1997) Economic Analysis of Property Rights. Cambridge: Cambridge University Press.

Brown, John S. and Paul Duguid (1998) 'Organizing Knowledge,' California Management Review 40 (3): 90-111.

Buckley, Peter J. and Martin J. Carter (1996) 'The Economics of Business Process Design: Motivation, Information, and Coordination Within the Firm,' International Journal of the Economics of Business, 33: 301-332.

Cabrera, A., W.C. Collins, and J.F. Salgado (2006) 'Determinants of Organizational Engagement in Knowledge Sharing,' International Journal of Human Resource Management 17: 245-264.

Child, John and Rita McGrath (2001) 'Organizations Unfettered: Organizational Form in an Information Intensive Economy,’ Academy of Management Journal 44: 1135-1148.

Clark, Kim B. and T. Fujimoto (1991) Product Development Performance: Strategy, Organisation and Management in the World Auto Industry. Boston: Harvard University Press.

Coase, Ronald H. (1937) 'The Nature of the Firm,’ Economica 4: 386-405.

Coase, Ronald H. (1960). 'The Problem of Social Cost,' Journal of Law and Economics 3: 144.

Coff, Russell (1999) 'When Competitive Advantage Doesn't Lead to Performance: Resourcebased Theory and Stakeholder Bargaining Power,' Organization Science 10: 119-133, 1999

Coff, Russell. and M. Blyler (2003) 'Dynamic Capabilities, Social Capital, and Rent Appropriation: Ties that Split Pies,’ Strategic Management Journal 24: 677-686.

Coleman, James S. (1990) Foundations of Social Theory. Cambridge (Mass.)/London: The Belknap Press of Harvard University Press.

Contractor, Farok J. and Wonchan Ra (2002) 'How Knowledge Attributes Influence Alliance Governance Choices,’ Journal of International Management 8: 11-27. 
Easterby-Smith, Mark and Marjorie A. Lyles, eds. (2003) Handbook of Organizational Learning and Knowledge Management. Oxford: Blackwell Publishing.

Foss, Nicolai J. (2003) 'Selective Intervention and Internal Hybrids: Interpreting and Learning from the Rise and Decline of the Oticon Spaghetti Organization.' Organization Science 14: 331-349.

Foss, Kirsten and Nicolai J. Foss (2005) 'Value and Transaction Costs,' Strategic Management Journal 26: 541-553.

Foss, Nicolai J. and Volker Mahnke (2003) 'Knowledge Management: What Does Organizational Economics Contribute?,' in Mark Easterby-Smith and Marjorie Lyles, eds. Handbook of Knowledge Management. Oxford: Basil Blackwell.

Grandori, Anna (1997) 'Governance Structures, Coordination Mechanisms and Cognitive Models,’ Journal of Management and Governance 1: 29-42.

Grandori, Anna (2001) 'Neither Hierarchy nor Identity: Knowledge Governance Mechanisms and the Theory of the Firm,' Journal of Management and Governance 5: 381-399.

Grandori, Anna and Bruce Kogut (2002) 'Dialogue on Organization and Knowledge,' Organization Science 13: 224-232.

Granovetter, Mark (1973) 'The Strength of Weak Ties,' American Journal of Sociology 78: 1360-1380.

Grant, Robert M. (1996) 'Towards a Knowledge-based Theory of the Firm,' Strategic Management Journal 17: 109-122.

Halal, William E. and K.B. Taylor (1998) Twenty-First Century Economics: Perspectives of Socioeconomics for a Changing World. New York: St. Martin’s Press.

Hamel, Gary (1991) 'Competition for competence and inter-partner learning within international strategic alliances,' Strategic Management Journal, 12: 83-103.

Hansen Morten T. (2002) 'Knowledge Networks: Explaining Effective Knowledge Sharing in Multiunit Companies,' Organization Science 13(3): 232-248

Hart, Oliver (1995) Firms, Contracts, and Financial Structure. Oxford: Oxford University Press.

Hayek, Friedrich A. von (1945) 'The Use of Knowledge in Society,' in idem. 1948. Individualism and economic order. Chicago: University of Chicago Press.

Hayek, F.A. von. (1952) The Counter-Revolution of Science. Chicago: University of Chicago Press.

Hedlund, Gunnar (1994) 'A Model of Knowledge Management and the N-Form Corporation,' Strategic Management Journal 15: 73-91.

Hedström, Peter and Richard Swedberg (1996) 'Social Mechanisms,' Acta Sociologica 39: 281308.

Heiman, Bruce and Jack A. Nickerson (2002) 'Towards Reconciling Transaction Cost Economics and the Knowledge-based View of the Firm: The Context of Interfirm Collaborations,' International Journal of the Economics of Business 9: 97-116.

Heiman, Bruce and Jack A. Nickerson (2004) 'Empirical Evidence Regarding the Tension Between Knowledge Sharing and Knowledge Expropriation in Collaborations,' Managerial and Decision Economics 25: 401-420. 
Heimeriks, Koen and Geert Duysters (2006) 'Alliance Capability as Mediator Between Experience and Alliance Capability,' Journal of Management Studies (forthcoming).

Hislop, David (2005) Knowledge Management in Organizations. Oxford: Oxford University Press.

Hoetker, Glenn and Thomas Mellewigt (2006) 'Matching Alliance Governance to Alliance Content,' in Africa Ariño and Jeff Reuer, eds., Strategic Alliances. Hampshire, U.K.: Palgrave Macmillan.

Holmström, Bengt and Paul Milgrom (1991) 'Multitask Principal-Agent Analyses: Incentive Contracts, Asset Ownership, and Job Design,' Journal of Law, Economics, and Organization 7: 24-52.

Jansen Justin J.P, Frans A.J. van den Bosch, and Henk W. Volberda (2006) 'Managing Potential and Realized Absorptive Capacity: How do Organizational Antecedents Matter?,' Academy of Management Journal 48: 999-1015

Jones, Gareth R. (1983) 'Transaction Costs, Property Rights, and Organizational Culture: An Exchange Perspective. _Administrative Science Quarterly 28: 454-467.

Kogut, Bruce and Udo Zander (1992) 'Knowledge of the Firm, Combinative Capabilities, and the Replication of Technology,’ Organization Science 3: 383-397.

Kogut, Bruce and Udo Zander (1993) 'Knowledge of the Firm and the Evolutionary Theory of the Multinational Corporation,’ Journal of International Business Studies 24: 625-645.

Kogut, Bruce and Udo Zander (1996) 'What Firms Do? Coordination, Identity, and Learning,' Organization Science 7: 502-518.

Kogut, Bruce (2000) "The Network as Knowledge: Generative Rules and the Emergence of Structure, “ Strategic Management Journal 21: 405-425.

Laursen, Keld and Nicolai J Foss (2003) 'New HRM Practices, Complementarities, and the Impact on Innovation Performance,' Cambridge Journal of Economics 27: 243-263.

Liebeskind, Julia P., Amalya A. Oliver, Lynne Zucker, and Marilyn Brewer (1996) 'Social Networks, Learning, and Flexibility: Sourcing Scientific Knowledge Among New Biotechnology Firms,' Organization Science 7: 428-443.

Lindenberg, Sigward (2003) 'The Cognitive Side of Governance,' Research in the Sociology of Organizations 20: 47-76.

Lippman, Steven A. and Richard P. Rumelt (2003) 'The Payments Perspective,' Strategic Management Journal 24: 903-927.

Lyles, Marjorie A. and Charles R. Schwenk (1992) 'Top Management Strategy and Organizational Knowledge,’ Journal of Management Studies 29(2): 155-174.

Machamer, P., L. Darden, and C.F. Craver (2000) 'Thinking About Mechanisms,' Philosophy of Science 67: 1-25.

Macher, Jeffrey. T. (2006) 'Technological Development and the Boundaries of the Firm,' Management Science 52 (6): 826-843.

Machlup, Fritz (1967) 'Theories of the Firm: Marginalist, Managerial and Behavioral,' in Fritz Machlup (1978) Essays on Economic Methodology. New York: Wiley.

Maritan, C.A. and T.H. Brush (2003) 'Heterogeneity and Transferring Practices: Implementing Flow Manufacturing in Multiple Plants,' Strategic Management Journal 24: 945-960. 
Mayer, Kyle and Nicholas Argyres (2004) 'Learning to Contract,' Organization Science 15: 394-410.

Milgrom, Paul and John Roberts (1990) 'The Economics of Modern Manufacturing: Technology, Strategy and Organization,' American Economic Review, 80: 511-528.

Minbaeva Dana, Torben Pedersen, Ingemar Björkman, Carl Fey, H.J. Park (2003) 'MNC Knowledge Transfer, Subsidiary Absorptive Capacity, and HRM,' Journal of International Business Studies 34: 586-599.

Mintzberg, Henry (1979) The Structuring of Organizations. Englewood Cliffs: Prentice-Hall.

Mowery, David C., Joanne Oxley, and Brian Silverman (1996) 'Strategic Alliances and Interfirm Knowledge Transfer,' Strategic Management Journal 17: 77-91.

Nelson, Richard R. and Sidney G. Winter (1982) The Evolutionary Theory of the Firm. Cambridge, MA: Harvard University Press.

Nickerson, Jackson and Todd Zenger (2004) 'A Knowledge-based Theory of the Firm: The Problem-Solving Perspective,’ Organization Science 15(6): 617-632

Osterloh, Margit and Bruno Frey (2000) 'Motivation, Knowledge Transfer and Organizational Form,’ Organization Science 11: 538-550.

Oxley, Joanne (1997) 'Appropriability Hazards and Governance in Strategic Alliances: a Transaction Cost Approach,’ Journal of Law, Economics, and Organization 13: 387-409.

Siggelkow, Nicolaj and Jan W. Rivkin (2005) 'Speed and Search: Designing Organizations for Turbulence and Complexity,’ Organization Science 16: 101-122.

Simonin, Bernard L. (1999) 'Transfer of Marketing Know-How in International Strategic Alliances,' Journal of International Business Studies 30: 463-490.

Spender, J.C. (1996) 'Making Knowledge the Basis of a Dynamic Theory of the Firm,' Strategic Management Journal 17 (Winter special issue): 45-62.

Spender, J.C. (2005) 'Review Article: An Essay of the State of Knowledge Management,' Prometheus 23: 101-116.

Starbuck, William (1992) 'Learning by Knowledge-Intensive Firms,' Journal of Management Studies 29: 713-41.

Tallman, Steven (2003) 'The Significance of Bruce Kogut's and Udo Zander's Article, 'Knowledge of the Firm and the Evolutionary Theory of the Multinational Morporation',' Journal of International Business Studies 34: 495-497.

Teece, David J. (2003) 'Expert Talent and the Design of (Professional Services) Firms,' Industrial and Corporate Change 12: 895-916.

Teece, David J., Gary Pisano and Amy Shuen (1997) 'Dynamic Capabilities and Strategic Management,' Strategic Management Journal 18: 509-534.

Tsai, W. P. (2001) 'Knowledge Transfer in Intra-organizational Networks,' Academy of Management Journal 44(5): 996-1004

Tsai, W. P. (2002) 'Social Structure of 'Coopetition' within a Multiunit Organization,' Organization Science 13: 179-190

Williamson, Oliver E. (1996) The Mechanisms of Governance. Oxford: Oxford University Press. 
Williamson, Oliver E. (1999) 'Strategy research: Governance and competence perspectives,' Strategic Management Journal, 20: 1087-1108.

Winter, Sidney G. (1987) 'Knowledge and Competence as Strategic Assets' in The Competitive Challenge. D. Teece (ed.), 159-184. Cambridge, MA: Ballinger. 